\title{
How Arsenic, an Inorganic Pollutant, is Involved in the Physiology of Biomolecular Condensates in the Cell
}

\author{
Osamu Udagawa * and Seishiro Hirano \\ Center for Health and Environmental Risk Research, National Institute for Environmental Studies, Tsukuba, Japan
}

OPEN ACCESS

Edited by:

Erik Björn,

Umeå University, Sweden

Reviewed by:

Bo Huang,

Xi'an Jiaotong University, China Natalia Sanchez De Groot, Universitat Autònoma de Barcelona,

Spain

*Correspondence:

Osamu Udagawa

udagawa.osamu@nies.go.jp

Specialty section:

This article was submitted to

Inorganic Pollutants,

a section of the journal

Frontiers in Environmental Chemistry

Received: 19 October 2021

Accepted: 27 January 2022

Published: 24 February 2022

Citation:

Udagawa O and Hirano S (2022) How Arsenic, an Inorganic Pollutant, is

Involved in the Physiology of

Biomolecular Condensates in the Cell.

Front. Environ. Chem. 3:797966.

doi: 10.3389/fenvc.2022.797966
The existence of membrane-less organelles in the cells has been known for a relatively long time. Of the membrane-less organelles, stress granules, processing bodies, and PML-NBs have been intensively investigated in relation to arsenic. The membrane-less organelles, which concentrate biomolecules (proteins, nucleic acids), have recently been shown to self-organize by means of phase separation/transition. These biomolecular condensates (membrane-less organelles) can provide local enhancement of the efficiency of specific reactions. The biomolecular condensates have attracted dramatic attention over the last decade because highly organized biochemical complexes in the cell have long been understood by the membranedependent compartmentalization. In this mini review, we highlight the initiation of phase separation for each biomolecular condensate in which arsenic could be involved. We further reflect on the adequacy of the arsenic-dependent ROS levels for the formation of biomolecular condensates. These perspectives led us to reevaluate the biological action of arsenic from a biophysical and bio-rheological point of view.

Keywords: phase separation, biomolecular condensates, stress granules, PML-NBs, arsenic

\section{INTRODUCTION}

Liquid-liquid phase separation (LLPS) is a physiologic cellular process during which some biomolecules such as proteins and RNA are highly concentrated in liquid droplet-like structures that are not surrounded by a lipid bilayer membrane. These droplet-like cellular structures such as bodies, granules, and speckles are known as biomolecular condensates. They are formed either in the cytoplasm or nucleus in response to changes in the intracellular environment (Banani et al., 2017) (Riback et al., 2020). The membrane-less property at the interface of each biomolecular condensate facilitates flow of water and solutes. Therefore, biomolecular condensates can be distinguished from aggregates with no fluidity. The aggregates can be formed irreversibly when the cell experiences the prolonged supersaturation of biomolecules (Shin et al., 2017). The features of interactions between proteins and biopolymers (e.g., stalled mRNA in stress granule formation) required to constitute biomolecular condensates are weak, multivalent, and dynamic. The protein domains that promote the formation of biomolecular condensates involve intrinsically disordered regions (IDRs), repeated modular domains, oligomerization domains, and/or substrate-binding (e.g., RNA-binding) domains (Hofmann et al., 2020) (Sabari et al., 2020). IDRs are regions that are often computationally predicted not to form fixed 3-D structures but rather are conformationally heterogeneous, and thus can engage in dynamic flexible multivalent interactions with partner molecules (Mittag and Parker, 2018). The valence as well as patterning of a collection of amino acid side chain interactions such as $\pi-\pi$ or cation- $\pi$ within 
TABLE 1 | Examples of biomolecular condensates in the cell.

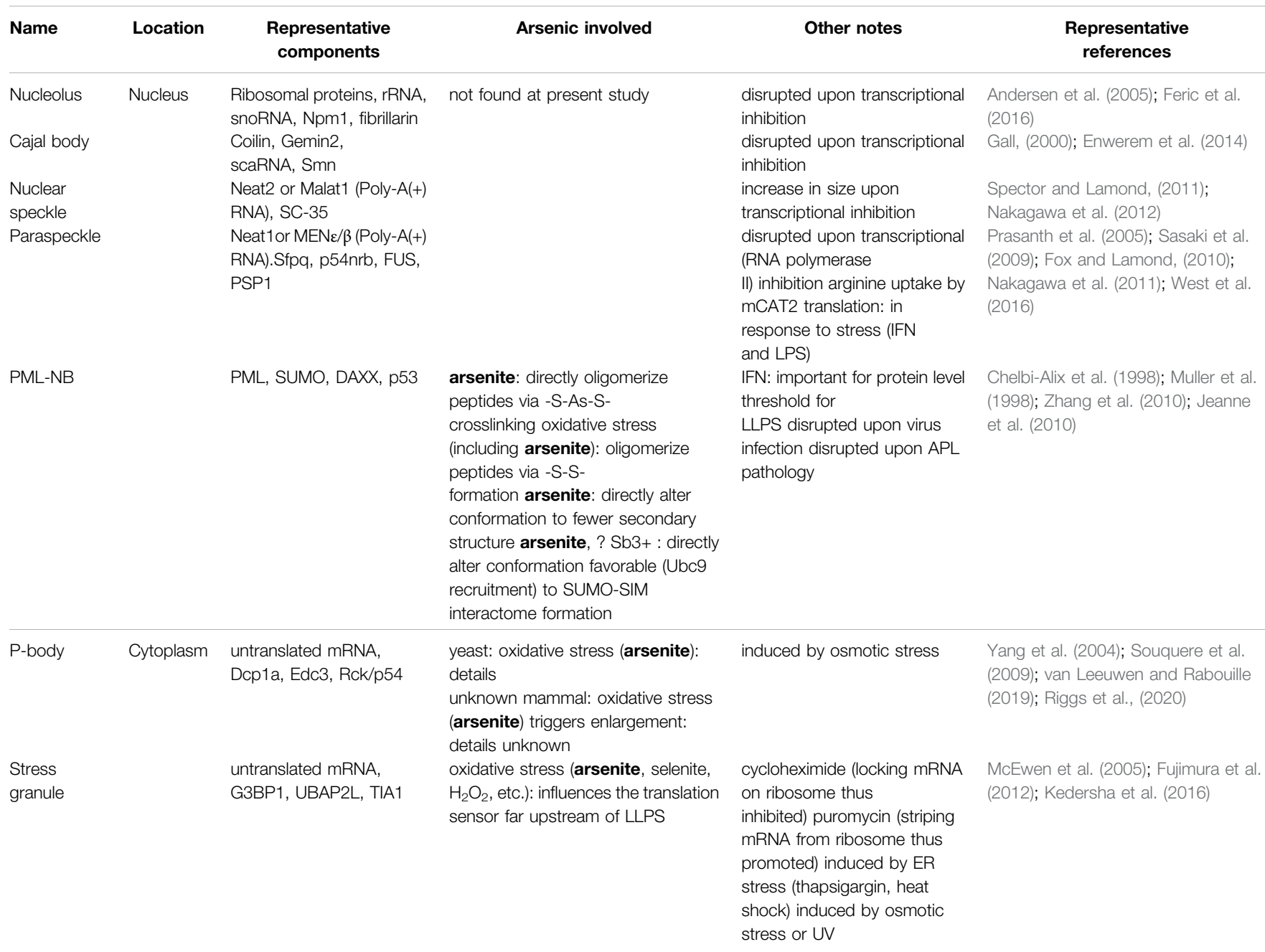

Abbreviations: P-body; Processing body, IFN; interferon, LPS; lipopolysaccharide, ER; endoplasmic reticulum, mCAT2; mouse cationic amino acid transporter 2, Sb; Antimony, APL; acute promyelocytic leukemia, SUMO; small ubiquitin-like modifier, SIM; SUMO interaction motif

IDRs contributes to LLPS in cells (Brangwynne et al., 2015) (Sabari et al., 2020). Mixing of proteins that each contain a different type of repeated modular domains results in liquid droplet formation ( $\mathrm{Li}$ et al., 2012). Li et al. used two proteins that contain tandemly arranged Src homology 3 domain and a proline-rich motif, respectively. The finding extended the idea that increased valence promotes LLPS.

The necessity of biomolecular condensates in cells is enigmatic if one simply considers the studies of mutant mice. For example, coilin (Cajal body resident) knockout mice are semi-lethal and shows reduced fecundity (Walker et al., 2009); plants with a mutation in coilin gene homozygously or flies of null mutants for coilin are fully viable (Nizami et al., 2010). Another example is Neat1 non-coding RNA (Paraspeckle resident); Neat ${ }^{-/-}$mice are normal (Nakagawa et al., 2011). Also, PML (promyelocytic leukemia-nuclear bodies (PML-NBs) resident) knockout mice develop normally (Niwa-Kawakita et al., 2017). However, biomolecular condensates may benefit various cellular processes by locally enhancing the reaction kinetics and specificities or by limiting reactions through temporal sequestration of biomolecules (Banani et al., 2017).

Explicit evidence indicates that arsenic is both a multi-organ carcinogen (IPCS, 2001) (Salnikow and Zhitkovich, 2008) (IARC Monogr Eval Carcinog Risks Hum, 2012) and a chemotherapeutic agent for certain cancers, such as acute promyelocytic leukemia (APL) (de The et al., 1991) (Kakizuka et al., 1991). This led to the notion that binding to cysteine residues is the initial step in a variety of arsenic-induced toxicological and pharmacological processes, because arsenite $\left(\mathrm{As}^{3+}\right)$ has a high affinity for thiol groups (Spuches et al., 2005) (Mizumura et al., 2010). Studies of arsenic trioxide $\left(\mathrm{As}_{2} \mathrm{O}_{3}\right)$ as a chemotherapeutic agent for the treatment of APL revealed that arsenite can particularly react with promyelocytic leukemia (PML) protein, a scaffold protein of PML-NBs. Now, PMLNBs are recognized to be one of the biomolecular condensates formed by LLPS. Since arsenic has not been well documented as a player for the LLPS, we discuss the involvement of arsenic in the formation of biomolecular condensates, considering stress granules and PML-NBs as examples. 
In this manuscript, we use the word "Nucleation" to describe the initiation step of LLPS.

\section{STRESS GRANULES}

\section{Physiology of Stress-Induced Biomolecular Condensates}

Stress granules are one of the most widely investigated biomolecular condensates in the cytoplasm (Table 1). Stress granule formation is considered to be an adaptive response to various acute stresses, acting to "triage" nascent mRNA from degradation and subsequent fitness upon stress relief (van Leeuwen and Rabouille, 2019). Actually, translational stalling triggered by stresses fine-tunes the cellular proteome by sorting housekeeping mRNA into stress granules, while excluding mRNA transcribed from stress-responsive genes (e.g., Hsp70, a molecular chaperone) from stress granules (Kedersha and Anderson, 2002). An example of an unfavorable cellular condition is viral infection. Stalling of viral mRNAs upon infection followed by stress granule formation plays a role in the cellular defense strategy against viral replication. However, if stress granules chronically persist in non-dividing cells (e.g., neurons) in particular, stress granules often contribute to the pathology accompanying protein aggregates (Riggs et al., 2020).

\section{Nucleation of Stress Granules}

Non-translating mRNA and abortive translation initiation complexes, which are released upon stress-triggered translational stalling, are both bound by RNA-binding proteins. Ras GTPase-activating protein-binding protein 1 (G3BP1) is an example of such an RNA-binding protein and is also called as stress granule nucleator (SG nucleator), because bona fide stress granules can be formed by G3BP1 overexpression even in the absence of stresses (Tourriere et al., 2003). G3BP1 centrally mediates the condensation of stalled mRNA and translation initiation complexes by locally enhancing their concentrations at foci (Kedersha et al., 2016) (Hofmann et al., 2020). G3BP1 not only has an RNA-binding domain, but also has IDRs and an oligomerization domain. Although IDRs are considered universal drivers for LLPS, IDRs in G3BP1 are dispensable for stress granule formation. Rather, an oligomerization domain at the N-terminus of G3BP1 highly contributes to interactive networks that increase the valence of G3BP1-RNA and drive LLPS (Sanders et al., 2020).

\section{Arsenite is not Directly Involved in Nucleation, but Influences the Translation Sensor far Upstream of Nucleation}

Two complementary regulatory mechanisms are largely responsible for stress-induced stalling of translational initiation: One is the preparation of ribosome-tRNA, and the other is the preparation of mRNA. Regarding the first mechanism, eukaryotic initiation factor 2 subunit alpha $(\mathrm{eIF} 2 \alpha)$ is essential for $43 \mathrm{~S}$ preinitiation complex (40S ribosomal subunit-eIF2 $\alpha-G T P-t R N A^{\text {Met }}$ ) assembly. Because the phosphorylated form of eIF $2 \alpha(\mathrm{eIF} 2 \alpha-P)$ firmly binds its guanine nucleotide exchange factor, eIF2B, which can exchange GDP only when eIF $2 \alpha$ is not phosphorylated, phosphorylation of eIF $2 \alpha$ inhibits reformation of eIF2 $\alpha$-GTP-tRNA ${ }^{\text {Met }}$ (Hinnebusch, 2014). Arsenite-induced $(200 \mu \mathrm{M}, 1 \mathrm{~h}, \mathrm{HAP} 1$ cells, human myeloid line) stress granule formation is mediated by hemeregulated inhibitor kinase (HRI) (Aulas et al., 2017), which is one of four kinases targeting eIF2 $\alpha$ : HRI, the mammalian homologue of yeast general control nonderepressible 2 (Gcn2p), protein kinase $\mathrm{R}$ (PKR), and PKR-like endoplasmic reticulum kinase (PERK) (McEwen et al., 2005). Mouse reticulocytes treated with arsenite $(200 \mu \mathrm{M}, \quad<1 \mathrm{~h})$ show autophosphorylation (i.e., activation) of HRI, which can be inhibited by pretreatment with the reactive oxygen species (ROS) scavenger, $\mathrm{N}$-acetyl-L-cysteine. However, adding arsenite to lysates in vitro does not activate HRI, suggesting that arsenite does not directly act on HRI but that ROS contribute (Lu et al., 2001). Consistent with this observation, arsenite has little effect on the activity of reconstituted HRI in vitro (Martinkova et al., 2007). Fetal liver cells obtained from $\mathrm{Hri}^{-1-}$ mice fail to recover from increased ROS levels induced by arsenite treatment, suggesting that HRI is required to mitigate acute oxidative stress (Suragani et al., 2012).

\section{PML-NBS}

\section{Physiology of Dynamically Modifiable Biomolecular Condensates}

Typically, approximately 5-20 PML-NBs are present per cell, with the size ranging from 0.2 to $1 \mu \mathrm{m}$. Although PML protein is an eponymous component of PML-NBs, more than 100 proteins are included inside PML-NBs. PML-NBs are ubiquitously distributed in adult organisms (Bernardi and Pandolfi, 2003) (Udagawa et al., 2021) and are involved in apoptosis, cell proliferation, senescence, tumor suppression, antiviral resistance, etc. (Salomoni and Pandolfi, 2002) (Maroui et al., 2012). Seven isoforms of human PML protein are known, of which PMLI-PMLVI have a nuclear localization signal and form PML-NBs (Nisole et al., 2013). All PML protein isoforms are tripartite motif (TRIM) family members that have an RBCC motif: Really Interesting New Gene (RING), two b-Boxes, and a coiled-coil domain. Interferons $(\alpha, \beta$, and $\gamma)$ drastically induce PML expression, leading to an increased number of swollen PMLNBs (Chelbi-Alix et al., 1995). The discovery of interplay between PML-NBs and innate immunity pushed the field forward. Producing proteins that colocalize with PML and have an ability to disrupt PML-NBs is one of the counter-adaptations for many viruses to deal with the intrinsic immunity of the host (Scherer and Stamminger, 2016) (van Gent et al., 2018). One example can be seen from a crystallographic analysis of the immediate early protein IE1 of primate cytomegalovirus. The analysis demonstrated the structural resemblance of core domain of IE1 to the coiled-coil domain of TRIM proteins. The similarity potentially endows IE1 to recognize PML/TRIM19 and subsequently, to antagonize the PML-mediated intrinsic 


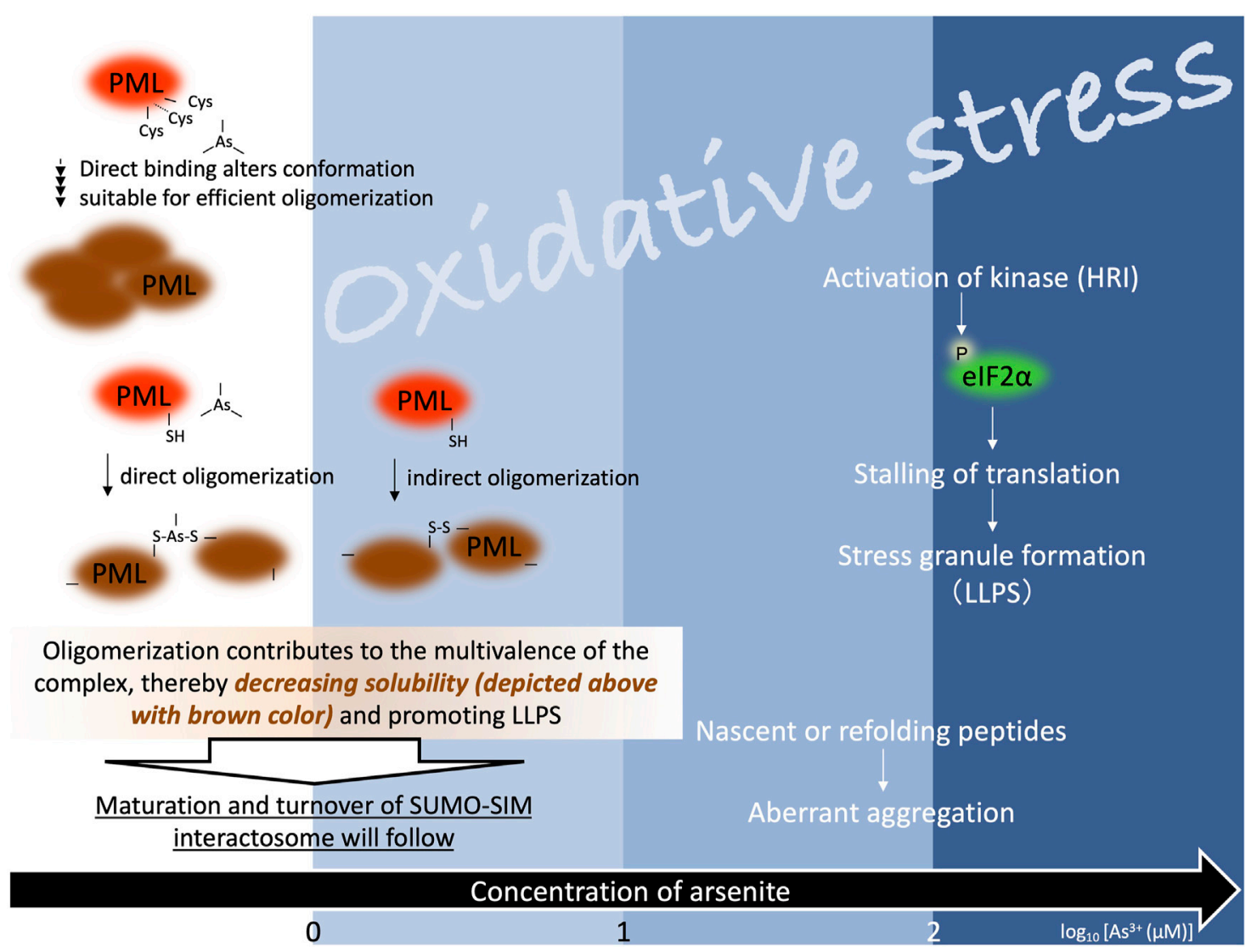

FIGURE 1 | Arsenite is involved in the formation of biomolecular condensates. The blue gradient colors represent different levels of oxidative stress at increasing concentration of arsenite. The numbers at the bottom indicate the logarithm of the arsenite concentration. Stress granule formation induced by higher concentration of arsenite is mediated by heme-regulated inhibitor kinase (HRI), which is one of four kinases targeting elF2 $\alpha$ (elF2 $\alpha$-P: phosphorylated form of eukaryotic initiation factor 2 subunit alpha) (dark blue panel, the right side of the figure). Arsenite-dependent solubility changes of PML protein can occur below the level of oxidative stress induction (white panel, the left side of the figure). Tetramerization of PML protein can occur in the absence of arsenite. Although how intra-molecular arsenic binding facilitates inter-molecular interactions is unknown, arsenite promotes oligomerization of PML protein. Further, regarding the promotion of inter-molecular interactions, arsenite acts as an indirect (i.e., oxidation-dependent -S-S- formation via oxidative stress) as well as direct (i.e., arsenic crosslinks PML polypeptides) oligomerizer. Like PML protein, client proteins in PML-NBs often possess small ubiquitin-like modifier (SUMO) conjugation sites and SUMO interaction motif (SIM). Arsenite-dependent solubility change of PML protein is followed by SUMOylation. SUMO-SIM-rich environment of PML-NBs is likely to be advantageous for multiple biological functions. SUMOylated PML protein is further ubiquitinated by the SUMO-dependent ubiquitin E3-ligase and adequately degraded via the ubiquitin-proteasome system.

immunity (Scherer et al., 2014). It is important to note that the antiviral activity of PML protein depends on the coiled-coil domain (Chelbi-Alix et al., 1998).

In the pathology of APL, PML-retinoic acid receptor $a$ fusion protein (PML-RARa, the $t(15 ; 17)$ gene translocation product) homo-dimerization via the coiled-coil domain of PML moiety promotes transcriptional repression of differentiation genes (Occhionorelli et al., 2011). At the same time, heterodimerization of PML-RARa with wild-type PML protein impedes PML protein oligomerization and adequate nucleation (see below), resulting in a micro-speckled appearance. Importantly, some retinoids capable of differentiating hematopoietic progenitor cells but not of degrading PMLRARa fail to induce remission of APL (Ablain et al., 2013). Retinoic acid can degrade PML-RARa and partly liberate wildtype PML protein to reform PML-NBs. Synergistic efficacy of arsenite and retinoic acid not only depends on the ability of arsenic to degrade PML-RAR $a$ but also to actively reform PMLNBs. Both PML-RARa degradation and PML-NB reformation induce p53-dependent senescence of APL-initiating cells, thereby inhibiting their self-renewal (Ablain et al., 2014) (de The, 2018).

\section{Nucleation of PML-NBs}

LLPS is dictated by a threshold concentration of the protein (Lee et al., 2020). Interferon-dependent augmentation of the PML protein level in the nucleoplasm (Chelbi-Alix et al., 1995), therefore serves as an important factor for nucleation of PML-NBs.

Given that PML protein is a sensitive ROS sensor (Sahin et al., 2014) (Niwa-Kawakita et al., 2017) and that prolonged treatment with $N$-acetyl-L-cysteine can deplete PML-NBs (Jeanne et al., 2010), oxidation-dependent -S-S- formation can stochastically oligomerize PML protein, which drives the nucleation of PML-NBs.

A recent crystallographic study on the RING domain of PML protein revealed that three residues (F52Q53F54) in a loop as well 
as L73 in the classic C3HC4-type RING finger motif constitute a PML/TRIM19-specific sequence among TRIM family proteins. The unique sequence is required for tetramerization of PML protein and for PML-NB nucleation (particularly L73) (Wang et al., 2018). A subsequent study showed the mode of RBCC oligomerization which is vital for PML-NB nucleation ( $\mathrm{Li}$ et al., 2019). Li et al. reported the crystal structure of the B1 domain of PML protein, showing that two bulky residues (W157 and F158), which are also unique to PML/TRIM19 among TRIM family proteins, are positioned at the oligomerization interface.

\section{Arsenite can Directly Promote Nucleation of PML-NBs}

Regarding the direct effect of arsenite on PML-NBs, we should look at two pieces of evidence on the direct binding mode of arsenic to PML protein. First lines of evidence are from Zhang et al., as follows. X-ray absorption spectroscopy data showed that arsenic coordinates with three sulfur atoms from conserved cysteines (C60/77/80 or C72/88/91). Circular dichroism analysis showed that the recombinant RING domain of PML protein titrated with arsenite showed fewer secondary structures than when stabilized by zinc. Twodimensional nuclear magnetic resonance (NMR) spectra revealed that arsenite-bound PML protein tends to oligomerize, which is clearly different from that of wellfolded zinc-bound PML protein. Further, a gel filtration assay demonstrated biochemically that arsenite-bound PML oligomers are primarily octamers that are largely sensitive to $6 \mathrm{M}$ urea; however, some remained as dimers. Authors hypothesized that these urea-resistant dimers would be maintained via arsenic-mediated crosslinking even in the denatured condition (Zhang et al., 2010). Although how intra-molecular arsenic binding activates inter-molecular interactions is unknown, these observations suggest that arsenite acts as an indirect as well as direct oligomerizer.

The latter evidence of the binding mode of arsenic on PML protein revealed that besides the RING domain, the B2 domain appears to be required. Biochemical analysis showed that arsenic binds to the $\mathrm{C} 212 / \mathrm{C} 213$ di-cysteines of the B2 domain. Data using the fluorescent diarsenical probe $\mathrm{FIAsH}$, which cooperatively binds two CC motifs (the fluorescence is dependent on C212/ C213), as well as stoichiometric analysis using atomic absorption suggested that arsenic crosslinks PML polypeptides. Also, the arsenic-binding defective $\mathrm{C} 212 \mathrm{~A}$ or $\mathrm{C} 213 \mathrm{~A}$ mutants exhibited strongly diffuse PML protein appearance in the nucleoplasm with only one or two abnormally enlarged PML structures (Jeanne et al., 2010), suggesting that arsenite acts as oligomerizer for the nucleation of PML-NBs.

\section{How Arsenite-Binding Alter PML/ TRIM19-Specific Region to Trigger LLPS?: A Potential Mechanism}

C3HC4-type RING conformation of PML determines higher selectivity to arsenite (Zhou et al., 2011) (Zhou et al., 2014) (Kaiming et al., 2018). Given that an in vitro experiment demonstrates that the perturbation of secondary structure of protein upon arsenite binding leads to oligomerization (Varma et al., 2018), partial unfolding of the secondary structure of PML protein upon arsenite-binding could trigger oligomerization of PML protein and subsequent nucleation of PML-NBs. Although much remains to be determined, the terminal of the helix in which $\mathrm{C} 77 / 80$, corresponding to $\mathrm{i} / \mathrm{i}+3$ arrangements of vicinal cysteines (Cline et al., 2003), locates can be destabilized by arsenite. The binding of arsenic will form disordered new conformations of PML protein around the tetramerization interface.

\section{Arsenite-Binding Subsequently Facilitates Maturation and Turnover of PML-NBs}

PML protein has the longest residence time (several minutes to $1 \mathrm{~h})$ compared to that of client proteins such as Sp100 and Daxx (several seconds to $1 \mathrm{~min}$ ) (Brand et al., 2010), reflecting that PML protein is the only scaffold protein of PML-NBs. Most human isoforms of PML protein have a small ubiquitin-like modifier (SUMO) interaction motif (SIM) that non-covalently interacts with SUMO or SUMOylated proteins. SUMOylation is a post-translational modification process regulating multiple cellular events such as gene expression and is mediated by SUMO conjugating enzyme, Ubc9. Like PML protein, client proteins including Ubc9 often possess SUMO conjugation sites and SIMs (Sahin et al., 2014). Importantly, the PML-3KR $\Delta$ SIM mutant, which is devoid of three lysine residues important for SUMOylation and SIM, can nucleate, suggesting that the nucleation of PML-NBs does not rely on SUMO-SIM (Lallemand-Breitenbach et al., 2001) (Sahin et al., 2014). However, given that poly-SUMO and poly-SIM synthetic peptides are used as a model of multivalent interactions between repeated modular domains (Banani et al., 2016), the SUMO-SIM-rich environment of PML-NBs is advantageous for maturation and integrity of this biomolecular condensate. The PML-3KR mutant indeed fails to recruit clients such as Sp100, SUMO1, and Daxx (Zhong et al., 2000). The recruitment of Ubc9 to PML-NBs was observed in $\mathrm{Pml}^{-/}$MEF cells stably coexpressed with PML protein and Ubc9, which were exposed to $1 \mu \mathrm{M}$ arsenite for $1 \mathrm{~h}$ (Wang et al., 2018). These results were consistent with the findings in in vitro assays in which arsenic binding altered the conformation of the RING domain of PML protein and enhanced RING-mediated interactions with Ubc9 (Zhang et al., 2010).

Although Ubc9 recruitment into PML-NBs favors hyperSUMOylation of multiple clients (Sahin et al., 2014), and would thus be beneficial for PML-NBs as an interactosome ( $\mathrm{Li}$ et al., 2019), SUMOylated PML protein is further ubiquitinated by the SUMO-dependent ubiquitin E3-ligase, RNF4, and degraded via the ubiquitin-proteasome system (LallemandBreitenbach and de The, 2010); this is common to an elimination mechanism for PML-RAR $\alpha$ fusion protein in APL pathology. Because prolonged supersaturation of biomolecular condensates can be pathologic as described, the SUMOdependent ubiquitin E3-ligase system may adequately prevent the aging of the gel-like state of PML-NBs. 


\section{DISCUSSION}

Arsenite induces the formation of stress granules at a very high, some hundreds of $\mu \mathrm{M}$, concentration. As in the case of stress granule induction, relatively lower concentration of arsenite produces ROS (Flora, 2011), and thus can at least in part indirectly contribute to the ROS-induced disulfides that crosslink PML protein (Jeanne et al., 2010). Some caution should be paid to this idea because theoretically upon exposure to excessive oxidants, critical protein thiols can be oxidized to transiently form protein sulfenic acid ( $\mathrm{PSOH}$ ) or protein sulfinic acid $\left(\mathrm{PSO}_{2} \mathrm{H}\right)$, or be fully oxidized into protein sulfonic acid $\left(\mathrm{PSO}_{3} \mathrm{H}\right)$ (i.e., inhibitory to oligomerization) (Jeanne et al., 2010). In this scenario, arsenite potentially serves as a reductant against protein sulfenic acid $(\mathrm{PSOH})$, reverting the protein to the thiol form (Saurin et al., 2004).

Oligomerization contributes to the multivalence of the complex, thereby decreasing solubility and promoting LLPS (Banani et al., 2017). Immunoblot analysis showed that most PML protein is detected in the detergent-soluble fraction, whereas in cells exposed to $0.1-1 \mu \mathrm{M}$ arsenite for $1-2 \mathrm{~h}$, almost all PML protein is detected in the detergent-insoluble fraction, which corresponds to the fraction associated with the nuclear matrix (Lallemand-Breitenbach et al., 2001) (Hirano et al., 2013) (Hirano et al., 2015). Examination of CHO cells stably transfected with an antioxidant responsive element demonstrated that promotor activation requires $1 \mu \mathrm{M}$ arsenite (with $6 \mathrm{~h}$ arsenite exposure), or requires at least $2 \mathrm{~h}$ (with $3 \mu \mathrm{M}$ arsenite exposure). Both are above the required levels for insolubilization (i.e., $0.1-1 \mu \mathrm{M}$ arsenite for $1-2 \mathrm{~h}$ ), suggesting that arsenite-dependent solubility changes of PML protein can occur below the level of oxidative stress induction (Hirano et al., 2013). For the illustration of concentration range, the plasma

\section{REFERENCES}

Ablain, J., Leiva, M., Peres, L., Fonsart, J., Anthony, E., and de Thé, H. (2013). Uncoupling RARA Transcriptional Activation and Degradation Clarifies the Bases for APL Response to Therapies. J. Exp. Med. 210, 647-653. doi:10.1084/ jem.20122337

Ablain, J., Rice, K., Soilihi, H., de Reynies, A., Minucci, S., and de Thé, H. (2014). Activation of a Promyelocytic Leukemia-Tumor Protein 53 axis Underlies Acute Promyelocytic Leukemia Cure. Nat. Med. 20, 167-174. doi:10.1038/nm.3441

Andersen, J. S., Lam, Y. W., Leung, A. K. L., Ong, S.-E., Lyon, C. E., Lamond, A. I., et al. (2005). Nucleolar Proteome Dynamics. Nature 433, 77-83. doi:10.1038/ nature03207

Au, W.-Y., Tam, S., Fong, B. M., and Kwong, Y.-L. (2008). Determinants of Cerebrospinal Fluid Arsenic Concentration in Patients with Acute Promyelocytic Leukemia on Oral Arsenic Trioxide Therapy. Blood 112, 3587-3590. doi:10.1182/blood-2008-06-161000

Aulas, A., Fay, M. M., Lyons, S. M., Achorn, C. A., Kedersha, N., Anderson, P., et al. (2017). Stress-specific Differences in Assembly and Composition of Stress Granules and Related Foci. J. Cel Sci 130, 927-937. doi:10.1242/jcs.199240

Banani, S. F., Lee, H. O., Hyman, A. A., and Rosen, M. K. (2017). Biomolecular Condensates: Organizers of Cellular Biochemistry. Nat. Rev. Mol. Cel Biol 18, 285-298. doi:10.1038/nrm.2017.7

Banani, S. F., Rice, A. M., Peeples, W. B., Lin, Y., Jain, S., Parker, R., et al. (2016). Compositional Control of Phase-Separated Cellular Bodies. Cell 166, 651-663. doi:10.1016/j.cell.2016.06.010 arsenic level in APL patients treated: ca. $0.5 \mu \mathrm{M}$ (Au et al., 2008); the provisional WHO guideline value of arsenic in drinkingwater: ca. $0.13 \mu \mathrm{M}$ (Ravenscroft et al., 2009).

It has been reported that many kinds of proteins before folding or during refolding are especially sensitive to higher concentration (i.e., comparable to that used in the induction of stress granule formation) of arsenite and heavy metals in vitro (Sharma et al., 2008) (Jacobson et al., 2012). If nascent protein in the cytosol is exposed to arsenite before being properly folded, it is expected that the protein has more chance to hyper-oligomerize resulting in aberrant aggregation because unfolded protein is conformationally mobile (Ramadan et al., 2009). Of note, the solubility changes of PML protein are not observed at all in HEK293 cells exposed to $\mathrm{Cd}^{2+}$ for $2 \mathrm{~h}$ even at an equivalent to the concentration of arsenite that efficiently promotes LLPS (Hirano et al., 2015). These suggest that arsenite-dependent solubility shift of PML protein is distinct from protein aggregation (Figure 1).

Finally, biomolecular condensates are related to many aspects of cellular physiology and communicate with neighboring membrane-bound organelles. Further investigations of spatiotemporal dynamics of biomolecular condensates should shed new light on biological activities of arsenic.

\section{AUTHOR CONTRIBUTIONS}

OU: Conceptualization, Writing. SH: Supervision, Writing.

\section{FUNDING}

This work was partially supported by a Grant-in-Aid from the Japan Society for the Promotion of Science (16K15386 to SH).

Bernardi, R., and Pandolfi, P. P. (2003). Role of PML and the PML-Nuclear Body in the Control of Programmed Cell Death. Oncogene 22, 9048-9057. doi:10.1038/ sj.onc. 1207106

Brand, P., Lenser, T., and Hemmerich, P. (2010). Assembly Dynamics of PML Nuclear Bodies in Living Cells. PMC Biophys. 3, 3. doi:10.1186/1757-5036-3-3

Brangwynne, C. P., Tompa, P., and Pappu, R. V. (2015). Polymer Physics of Intracellular Phase Transitions. Nat. Phys 11, 899-904. doi:10.1038/nphys3532

Chelbi-Alix, M. K., Pelicano, L., Quignon, F., Koken, M. H., Venturini, L., Stadler, M., et al. (1995). Induction of the PML Protein by Interferons in normal and APL Cells. Leukemia 9, 2027-2033. https://pubmed.ncbi.nlm.nih.gov/8609713/.

Chelbi-Alix, M. K., Quignon, F., Pelicano, L., Koken, M. H. M., and de The', H. (1998). Resistance to Virus Infection Conferred by the Interferon-Induced Promyelocytic Leukemia Protein. J. Virol. 72, 1043-1051. doi:10.1128/jvi.72.2. 1043-1051.1998

Cline, D. J., Thorpe, C., and Schneider, J. P. (2003). Effects of As(III) Binding on aHelical Structure. J. Am. Chem. Soc. 125, 2923-2929. doi:10.1021/ja0282644

de Thé, H. (2018). Differentiation Therapy Revisited. Nat. Rev. Cancer 18, 117-127. doi: $10.1038 /$ nrc.2017.103

de Thé, H., Lavau, C., Marchio, A., Chomienne, C., Degos, L., and Dejean, A. (1991). The PML-Rara Fusion mRNA Generated by the T(15;17) Translocation in Acute Promyelocytic Leukemia Encodes a Functionally Altered RAR. Cell 66, 675-684. doi:10.1016/0092-8674(91)90113-d

EnweremII, Velma, V., Broome, H. J., Kuna, M., Begum, R. A., and Hebert, M. D. (2014). Coilin Association with Box C/D scaRNA Suggests a Direct Role for the Cajal Body Marker Protein in scaRNP Biogenesis. Biol. Open 3, 240-249. doi:10. 1242/bio.20147443 
Feric, M., Vaidya, N., Harmon, T. S., Mitrea, D. M., Zhu, L., Richardson, T. M., et al. (2016). Coexisting Liquid Phases Underlie Nucleolar Subcompartments. Cell 165, 1686-1697. doi:10.1016/j.cell.2016.04.047

Flora, S. J. S. (2011). Arsenic-induced Oxidative Stress and its Reversibility. Free Radic. Biol. Med. 51, 257-281. doi:10.1016/j.freeradbiomed.2011.04.008

Fox, A. H., and Lamond, A. I. (2010). Paraspeckles. Cold Spring Harbor Perspect. Biol. 2, a000687. doi:10.1101/cshperspect.a000687

Fujimura, K., Sasaki, A. T., and Anderson, P. (2012). Selenite Targets eIF4EBinding Protein-1 to Inhibit Translation Initiation and Induce the Assembly of Non-canonical Stress Granules. Nucleic Acids Res. 40, 8099-8110. doi:10.1093/ nar/gks566

Gall, J. G. (2000). Cajal Bodies: the First 100 Years. Annu. Rev. Cel Dev. Biol. 16, 273-300. doi:10.1146/annurev.cellbio.16.1.273

Hinnebusch, A. G. (2014). The Scanning Mechanism of Eukaryotic Translation Initiation. Annu. Rev. Biochem. 83, 779-812. doi:10.1146/annurev-biochem060713-035802

Hirano, S., Tadano, M., Kobayashi, Y., Udagawa, O., and Kato, A. (2015). Solubility Shift and SUMOylaltion of Promyelocytic Leukemia (PML) Protein in Response to Arsenic(III) and Fate of the SUMOylated PML. Toxicol. Appl. Pharmacol. 287, 191-201. doi:10.1016/j.taap.2015.05.018

Hirano, S., Watanabe, T., and Kobayashi, Y. (2013). Effects of Arsenic on Modification of Promyelocytic Leukemia (PML): PML Responds to Low Levels of Arsenite. Toxicol. Appl. Pharmacol. 273, 590-599. doi:10.1016/j. taap.2013.10.004

Hofmann, S., Kedersha, N., Anderson, P., and Ivanov, P. (2020). Molecular Mechanisms of Stress Granule Assembly and Disassembly. Biochim. Biophys. Acta Mol. Cel Res 1868, 118876. doi:10.1016/j.bbamcr.2020.118876

IARC Monogr Eval Carcinog Risks Hum (2012). Arsenic, Metals, Fibres, and Dusts. IARC Monogr. Eval. Carcinog Risks Hum. 100, 11-465. http://www.ncbi. nlm.nih.gov/pubmed/23189751.

IPCS (2001). Arsenic and Arsenic Compounds. Geneva: World Health Organization.

Jacobson, T., Navarrete, C., Sharma, S. K., Sideri, T. C., Ibstedt, S., Priya, S., et al. (2012). Arsenite Interferes with Protein Folding and Triggers Formation of Protein Aggregates in Yeast. J. Cel Sci 125, 5073-5083. doi:10.1242/jcs.107029

Jeanne, M., Lallemand-Breitenbach, V., Ferhi, O., Koken, M., Le Bras, M., Duffort, S., et al. (2010). PML/RARA Oxidation and Arsenic Binding Initiate the Antileukemia Response of As2O3. Cancer Cell 18, 88-98. doi:10.1016/j.ccr. 2010.06.003

Kaiming, C., Sheng, Y., Zheng, S., Yuan, S., Huang, G., and Liu, Y. (2018). Arsenic Trioxide Preferentially Binds to the Ring finger Protein PML: Understanding Target Selection of the Drug. Metallomics 10, 1564-1569. doi:10.1039/c8mt00202a

Kakizuka, A., Miller, W. H., Jr., Umesono, K., Warrell, R. P., Jr., Frankel, S. R., Murty, V. V. V. S., et al. (1991). Chromosomal Translocation T(15;17) in Human Acute Promyelocytic Leukemia Fuses RAR $\alpha$ with a Novel Putative Transcription Factor, PML. Cell 66, 663-674. doi:10.1016/0092-8674(91) 90112-c

Kedersha, N., Panas, M. D., Achorn, C. A., Lyons, S., Tisdale, S., Hickman, T., et al. (2016). G3BP-Caprin1-USP10 Complexes Mediate Stress Granule Condensation and Associate with 40S Subunits. J. Cel Biol 212 (60), 845. doi:10.1083/jcb.201508028

Kedersha, N., and Anderson, P. (2002). Stress Granules: Sites of mRNA Triage that Regulate mRNA Stability and Translatability. Biochem. Soc. Trans. 30, 963-969. doi:10.1042/bst0300963

Lallemand-Breitenbach, V., and de The, H. (2010). PML Nuclear Bodies. Cold Spring Harbor Perspect. Biol. 2, a000661. doi:10.1101/cshperspect.a000661

Lallemand-Breitenbach, V., Zhu, J., Puvion, F., Koken, M., Honoré, N., Doubeikovsky, A., et al. (2001). Role of Promyelocytic Leukemia (Pml) Sumolation in Nuclear Body Formation, 11s Proteasome Recruitment, and as2O3-Induced Pml or Pml/Retinoic Acid Receptor a Degradation. J. Exp. Med. 193, 1361-1372. doi:10.1084/jem.193.12.1361

Lee, A. K., Klein, J., Fon Tacer, K., Lord, T., Oatley, M. J., Oatley, J. M., et al. (2020). Translational Repression of G3BP in Cancer and Germ Cells Suppresses Stress Granules and Enhances Stress Tolerance. Mol. Cel 79, 645-659. doi:10.1016/j. molcel.2020.06.037

Li, P., Banjade, S., Cheng, H.-C., Kim, S., Chen, B., Guo, L., et al. (2012). Phase Transitions in the Assembly of Multivalent Signalling Proteins. Nature 483, 336-340. doi:10.1038/nature10879
Li, Y., Ma, X., Chen, Z., Wu, H., Wang, P., Wu, W., et al. (2019). B1 Oligomerization Regulates PML Nuclear Body Biogenesis and Leukemogenesis. Nat. Commun. 10, 3789. doi:10.1038/s41467-019-11746-0

Lu, L., Han, A.-P., and Chen, J.-J. (2001). Translation Initiation Control by HemeRegulated Eukaryotic Initiation Factor $2 \alpha$ Kinase in Erythroid Cells under Cytoplasmic Stresses. Mol. Cel Biol 21, 7971-7980. doi:10.1128/mcb.21.23. 7971-7980.2001

Maroui, M. A., Kheddache-Atmane, S., El Asmi, F., Dianoux, L., Aubry, M., and Chelbi-Alix, M. K. (2012). Requirement of PML SUMO Interacting Motif for RNF4- or Arsenic Trioxide-Induced Degradation of Nuclear PML Isoforms. PLoS One 7, e44949. doi:10.1371/journal.pone.0044949

Martinkova, M., Igarashi, J., and Shimizu, T. (2007). Eukaryotic Initiation Factor $2 a$ Kinase Is a Nitric Oxide-Responsive Mercury Sensor Enzyme: Potent Inhibition of Catalysis by the Mercury Cation and Reversal by Nitric Oxide. FEBS Lett. 581, 4109-4114. doi:10.1016/j.febslet.2007.07.055

McEwen, E., Kedersha, N., Song, B., Scheuner, D., Gilks, N., Han, A., et al. (2005). Heme-regulated Inhibitor Kinase-Mediated Phosphorylation of Eukaryotic Translation Initiation Factor 2 Inhibits Translation, Induces Stress Granule Formation, and Mediates Survival upon Arsenite Exposure. J. Biol. Chem. 280, 16925-16933. doi:10.1074/jbc.m412882200

Mittag, T., and Parker, R. (2018). Multiple Modes of Protein-Protein Interactions Promote RNP Granule Assembly. J. Mol. Biol. 430, 4636-4649. doi:10.1016/j. jmb.2018.08.005

Mizumura, A., Watanabe, T., Kobayashi, Y., and Hirano, S. (2010). Identification of Arsenite-And Arsenic Diglutathione-Binding Proteins in Human Hepatocarcinoma Cells. Toxicol. Appl. Pharmacol. 242, 119-125. doi:10. 1016/j.taap.2009.10.013

Müller, S., Miller, W. H., Jr., and Dejean, A. (1998). Trivalent Antimonials Induce Degradation of the PML-RAR Oncoprotein and Reorganization of the Promyelocytic Leukemia Nuclear Bodies in Acute Promyelocytic Leukemia NB4 Cells. Blood 92, 4308-4316. doi:10.1182/blood.V92.11.4308

Nakagawa, S., Ip, J. Y., Shioi, G., Tripathi, V., Zong, X., Hirose, T., et al. (2012). Malat1 Is Not an Essential Component of Nuclear Speckles in Mice. RNA 18, 1487-1499. doi:10.1261/rna.033217.112

Nakagawa, S., Naganuma, T., Shioi, G., and Hirose, T. (2011). Paraspeckles Are Subpopulation-specific Nuclear Bodies that Are Not Essential in Mice. J. Cel Biol 193, 31-39. doi:10.1083/jcb.201011110

Nisole, S., Maroui, M. A., Mascle, X. H., Aubry, M., and Chelbi-Alix, M. K. (2013). Differential Roles of PML Isoforms. Front. Oncol. 3, 125. doi:10.3389/fonc.2013. 00125

Niwa-Kawakita, M., Ferhi, O., Soilihi, H., Le Bras, M., Lallemand-Breitenbach, V., and de Thé, H. (2017). PML Is a ROS Sensor Activating P53 upon Oxidative Stress. J. Exp. Med. 214, 3197-3206. doi:10.1084/jem.20160301

Nizami, Z., Deryusheva, S., and Gall, J. G. (2010). The Cajal Body and Histone Locus Body. Cold Spring Harbor Perspect. Biol. 2, a000653. doi:10.1101/ cshperspect.a000653

Occhionorelli, M., Santoro, F., Pallavicini, I., Gruszka, A., Moretti, S., Bossi, D., et al. (2011). The Self-Association Coiled-Coil Domain of PML Is Sufficient for the Oncogenic Conversion of the Retinoic Acid Receptor (RAR) Alpha. Leukemia 25, 814-820. doi:10.1038/leu.2011.18

Prasanth, K. V., Prasanth, S. G., Xuan, Z., Hearn, S., Freier, S. M., Bennett, C. F., et al. (2005). Regulating Gene Expression through RNA Nuclear Retention. Cell 123, 249-263. doi:10.1016/j.cell.2005.08.033

Ramadan, D., Rancy, P. C., Nagarkar, R. P., Schneider, J. P., and Thorpe, C. (2009). Arsenic(III) Species Inhibit Oxidative Protein Folding In Vitro. Biochemistry 48, 424-432. doi:10.1021/bi801988x

Ravenscroft, P., Brammer, H., and Richards, K. (2009). Arsenic Pollution: A Global Synthesis. John Wiley \& Sons.

Riback, J. A., Zhu, L., Ferrolino, M. C., Tolbert, M., Mitrea, D. M., Sanders, D. W., et al. (2020). Composition-dependent Thermodynamics of Intracellular Phase Separation. Nature 581, 209-214. doi:10.1038/s41586-020-2256-2

Riggs, C. L., Kedersha, N., Ivanov, P., and Anderson, P. (2020). Mammalian Stress Granules and P Bodies at a Glance. J. Cel Sci 133. doi:10.1242/jcs. 242487

Sabari, B. R., Dall'Agnese, A., and Young, R. A. (2020). Biomolecular Condensates in the Nucleus. Trends Biochem. Sci. 45, 961-977. doi:10.1016/j.tibs.2020.06.007

Sahin, U., Ferhi, O., Jeanne, M., Benhenda, S., Berthier, C., Jollivet, F., et al. (2014) Oxidative Stress-Induced Assembly of PML Nuclear Bodies Controls 
Sumoylation of Partner Proteins. J. Cel Biol 204, 931-945. doi:10.1083/jcb. 201305148

Salnikow, K., and Zhitkovich, A. (2008). Genetic and Epigenetic Mechanisms in Metal Carcinogenesis and Cocarcinogenesis: Nickel, Arsenic, and Chromium. Chem. Res. Toxicol. 21, 28-44. doi:10.1021/tx700198a

Salomoni, P., and Pandolfi, P. P. (2002). The Role of PML in Tumor Suppression. Cell 108, 165-170. doi:10.1016/s0092-8674(02)00626-8

Sanders, D. W., Kedersha, N., Lee, D. S. W., Strom, A. R., Drake, V., Riback, J. A., et al. (2020). Competing Protein-RNA Interaction Networks Control Multiphase Intracellular Organization. Cell 181, 306-324. doi:10.1016/j.cell.2020.03.050

Sasaki, Y. T. F., Ideue, T., Sano, M., Mituyama, T., and Hirose, T. (2009). Mene/ $\beta$ Noncoding RNAs Are Essential for Structural Integrity of Nuclear Paraspeckles. Pnas 106, 2525-2530. doi:10.1073/pnas.0807899106

Saurin, A. T., Neubert, H., Brennan, J. P., and Eaton, P. (2004). Widespread Sulfenic Acid Formation in Tissues in Response to Hydrogen Peroxide. Proc. Natl. Acad. Sci. 101, 17982-17987. doi:10.1073/pnas.0404762101

Scherer, M., Klingl, S., Sevvana, M., Otto, V., Schilling, E.-M., Stump, J. D., et al. (2014). Crystal Structure of Cytomegalovirus IE1 Protein Reveals Targeting of TRIM Family Member PML via Coiled-Coil Interactions. Plos Pathog. 10, e1004512. doi:10.1371/journal.ppat.1004512

Scherer, M., and Stamminger, T. (2016). Emerging Role of PML Nuclear Bodies in Innate Immune Signaling. J. Virol. 90, 5850-5854. doi:10.1128/jvi.01979-15

Sharma, S. K., Goloubinoff, P., and Christen, P. (2008). Heavy Metal Ions Are Potent Inhibitors of Protein Folding. Biochem. Biophysical Res. Commun. 372, 341-345. doi:10.1016/j.bbrc.2008.05.052

Shin, Y., Berry, J., Pannucci, N., Haataja, M. P., Toettcher, J. E., and Brangwynne, C. P. (2017). Spatiotemporal Control of Intracellular Phase Transitions Using Light-Activated optoDroplets. Cell 168, 159-171. doi:10.1016/j.cell.2016.11.054

Souquere, S., Mollet, S., Kress, M., Dautry, F., Pierron, G., and Weil, D. (2009). Unravelling the Ultrastructure of Stress Granules and Associated P-Bodies in Human Cells. J. Cel Sci 122, 3619-3626. doi:10.1242/jcs.054437

Spector, D. L., and Lamond, A. I. (2011). Nuclear Speckles. Cold Spring Harb Perspect. Biol. 3. doi:10.1101/cshperspect.a000646

Spuches, A. M., Kruszyna, H. G., Rich, A. M., and Wilcox, D. E. (2005). Thermodynamics of the As(III)-Thiol Interaction: Arsenite and Monomethylarsenite Complexes with Glutathione, Dihydrolipoic Acid, and Other Thiol Ligands. Inorg. Chem. 44, 2964-2972. doi:10.1021/ic048694q

Suragani, R. N. V. S., Zachariah, R. S., Velazquez, J. G., Liu, S., Sun, C.-W., Townes, T. M., et al. (2012). Heme-regulated eIF2 $\alpha$ Kinase Activated Atf4 Signaling Pathway in Oxidative Stress and Erythropoiesis. Blood 119, 5276-5284. doi:10. 1182/blood-2011-10-388132

Tourrière, H., Chebli, K., Zekri, L., Courselaud, B., Blanchard, J. M., Bertrand, E., et al. (2003). The RasGAP-Associated Endoribonuclease G3BP Assembles Stress Granules. J. Cel Biol 160, 823-831. doi:10.1083/jcb.200212128

Udagawa, O., Kato-Udagawa, A., and Hirano, S., 2021. Promyelocytic Leukemia Nuclear Body (PML-NB) -free Intranuclear Milieu Facilitates Development of Oocytes in Mice. bioRxiv. doi:10.1101/2021.09.06.458940

van Gent, M., Sparrer, K. M. J., and Gack, M. U. (2018). TRIM Proteins and Their Roles in Antiviral Host Defenses. Annu. Rev. Virol. 5, 385-405. doi:10.1146/ annurev-virology-092917-043323

van Leeuwen, W., and Rabouille, C. (2019). Cellular Stress Leads to the Formation of Membraneless Stress Assemblies in Eukaryotic Cells. Traffic 20, 623-638. doi:10.1111/tra.12669
Varma, N., Singh, I., Dahiya, M. S., Ravi, V. K., and Kumar, S. (2018). Structural Perturbation by Arsenic Triggers the Aggregation of Hen Egg white Lysozyme by Promoting Oligomers Formation. Int. J. Biol. Macromolecules 109, 1108-1114. doi:10.1016/j.ijbiomac.2017.11.096

Walker, M. P., Tian, L., and Matera, A. G. (2009). Reduced Viability, Fertility and Fecundity in Mice Lacking the Cajal Body Marker Protein, Coilin. PLoS One 4, e6171. doi:10.1371/journal.pone.0006171

Wang, P., Benhenda, S., Wu, H., Lallemand-Breitenbach, V., Zhen, T., Jollivet, F., et al. (2018). RING Tetramerization Is Required for Nuclear Body Biogenesis and PML Sumoylation. Nat. Commun. 9, 1277. doi:10.1038/s41467-01803498-0

West, J. A., Mito, M., Kurosaka, S., Takumi, T., Tanegashima, C., Chujo, T., et al. (2016). Structural, Super-resolution Microscopy Analysis of Paraspeckle Nuclear Body Organization. J. Cel Biol 214, 817-830. doi:10.1083/jcb. 201601071

Yang, Z., Jakymiw, A., Wood, M. R., Eystathioy, T., Rubin, R. L., Fritzler, M. J., et al. (2004). GW182 Is Critical for the Stability of GW Bodies Expressed during the Cell Cycle and Cell Proliferation. J. Cel Sci 117, 5567-5578. doi:10.1242/jcs. 01477

Zhang, X.-W., Yan, X.-J., Zhou, Z.-R., Yang, F.-F., Wu, Z.-Y., Sun, H.-B., et al. (2010). Arsenic Trioxide Controls the Fate of the PML-Rara Oncoprotein by Directly Binding PML. Science 328, 240-243. doi:10.1126/science. 1183424

Zhong, S., Muiller, S., Ronchetti, S., Freemont, P. S., Dejean, A., and Pandolfi, P. P. (2000). Role of SUMO-1-Modified PML in Nuclear Body Formation. Blood J. Am. Soc. Hematol. 95, 2748-2752. doi:10.1182/blood.v95.9.2748. 009k31a_2748_2752

Zhou, X., Sun, X., Cooper, K. L., Wang, F., Liu, K. J., and Hudson, L. G. (2011). Arsenite Interacts Selectively with Zinc finger Proteins Containing C3H1 or C4 Motifs. J. Biol. Chem. 286, 22855-22863. doi:10.1074/jbc.m111. 232926

Zhou, X., Sun, X., Mobarak, C., Gandolfi, A. J., Burchiel, S. W., Hudson, L. G., et al. (2014). Differential Binding of Monomethylarsonous Acid Compared to Arsenite and Arsenic Trioxide with Zinc finger Peptides and Proteins. Chem. Res. Toxicol.27,690-698. doi:10.1021/ tx500022j

Conflict of Interest: The authors declare that the research was conducted in the absence of any commercial or financial relationships that could be construed as a potential conflict of interest.

Publisher's Note: All claims expressed in this article are solely those of the authors and do not necessarily represent those of their affiliated organizations, or those of the publisher, the editors, and the reviewers. Any product that may be evaluated in this article, or claim that may be made by its manufacturer, is not guaranteed or endorsed by the publisher.

Copyright (๑) 2022 Udagawa and Hirano. This is an open-access article distributed under the terms of the Creative Commons Attribution License (CC BY). The use, distribution or reproduction in other forums is permitted, provided the original author(s) and the copyright owner(s) are credited and that the original publication in this journal is cited, in accordance with accepted academic practice. No use, distribution or reproduction is permitted which does not comply with these terms. 